\title{
Charge Trapping Properties of 3C- and 4H-SiC MOS Capacitors With Nitrided Gate Oxides
}

\author{
Rajan Arora, Student Member, IEEE, John Rozen, Daniel M. Fleetwood, Fellow, IEEE, \\ Kenneth F. Galloway, Fellow, IEEE, C. Xuan Zhang, Student Member, IEEE, Jisheng Han, \\ Sima Dimitrijev, Senior Member, IEEE, Fred Kong, Leonard C. Feldman, Member, IEEE, \\ Sokrates T. Pantelides, Member, IEEE, and Ronald D. Schrimpf, Fellow, IEEE
}

\begin{abstract}
Silicon-carbide-based MOS capacitors were formed on either $3 \mathrm{C}$ (epitaxial on $\mathrm{Si}$ ) or $4 \mathrm{H}$ substrates and using $\mathrm{SiO}_{2}$ gate dielectrics both with and without interfacial nitrogen. The charge trapping properties of these structures were examined after exposure to ionizing radiation. In all cases interfacial nitrogen results in improved trap density and increased oxide charge trapping. For equivalent nitrogen content, $3 \mathrm{C}$-based devices exhibit more charge trapping than the $4 \mathrm{H}$-based equivalents.
\end{abstract}

Index Terms-MOS, NO, $\mathrm{N}_{2} \mathrm{O}, \mathrm{POA}, 3 \mathrm{C}-\mathrm{SiC}, 4 \mathrm{H}-\mathrm{SiC}$.

\section{INTRODUCTION}

$\mathbf{S}$ ILICON CARBIDE ( $\mathrm{SiC})$ is a candidate material for highpower and high-frequency electronic devices due to its excellent thermal conductivity and high breakdown field [1], [2]. It is preferred over other wide band gap semiconductors because $\mathrm{SiO}_{2}$ can be thermally grown to form the gate oxide [3], [4]. In addition, $\mathrm{SiC}$ has excellent thermal and chemical stability, a large saturation drift velocity and high bulk electron mobility.

Manuscript received July 17, 2009; revised August 25, 2009. Current version published December 09, 2009. This work was supported in part by the U.S. Air Force Office of Scientific Research (AFOSR) through the MURI program and in part by U.S. Army Research Grants W911NF-07-2-0046 and W56HZV-06-C0228 .

R. Arora was with the Department of Electrical Engineering and Computer Science (EECS), Vanderbilt University, Nashville, TN 37235 USA. He is now with the School of Electrical and Computer Engineering, Georgia Institute of Technology, Atlanta, GA 30332-0250 USA (e-mail: arora@ece.gatech.edu).

J. Rozen is with the Department of Physics and Astronomy, Vanderbilt University, Nashville, TN 37235 USA and also with the Central Research Institute of Electric Power Industry (CRIEPI), Yokosuka, Kanagawa 240-0196, Japan (e-mail: john.rozen@ vanderbilt.edu).

D. M. Fleetwood, K. F. Galloway, C. X. Zhang, and R. D. Schrimpf are with the Department of Electrical Engineering and Computer Science (EECS), Vanderbilt University, Nashville, TN 37235 USA (e-mail: dan.fleetwood@vanderbilt.edu; ken.galloway@vanderbilt.edu; xuan.zhang@vanderbilt.edu; ron.schrimpf@vanderbilt.edu).

J. Han and F. Kong are with Queensland Microtechnology Facility, Griffith University, Queensland, Australia (e-mail: j.han@ griffith.edu.au; f.kong @ griffith.edu.au).

S. Dimitrijev is with Queensland Microtechnology Facility, Griffith School of Engineering, Griffith University, Queensland, Australia (e-mail: s.dimitrijev@griffith.edu.au).

L. C. Feldman is with the Department of Physics and Astronomy, Vanderbilt University, Nashville, TN 37235 USA and also with the Institute of Advanced Materials, Devices and Nanotechnology, Rutgers, The State University of New Jersey, Piscataway, NJ 08854 USA (e-mail: 1.c.feldman@ rutgers.edu).

S. T. Pantelides is with the Department of Physics and Astronomy, Vanderbilt University, Nashville, TN 37235 USA (e-mail: pantelides@ vanderbilt.edu).

Color versions of one or more of the figures in this paper are available online at http://ieeexplore.ieee.org.

Digital Object Identifier 10.1109/TNS.2009.2031604
$\mathrm{SiC}$ exists under stoichiometrically equivalent crystalline structures called polytypes. The $4 \mathrm{H}-\mathrm{SiC}$ polytype has received more attention compared to others due to its greater band gap, combined with a high and more isotropic bulk carrier mobility [5]. Among the other $\mathrm{SiC}$ polytypes, cubic silicon-carbide (3C-SiC) is another promising candidate for electronic applications because of its compatibility with Si CMOS technology [6].

Historically, 4H-SiC MOSFETs have suffered from low inversion channel mobilities due to extremely high interface trap densities in un-passivated devices $\left(D_{i t}\right.$ close to the $4 \mathrm{H}-\mathrm{SiC}$ conduction band-edge $\sim 10^{13} \mathrm{~cm}^{-2} \mathrm{eV}^{-1}$ ). Annealing in hydrogen, which is a key in improving the quality of the interface in $\mathrm{SiO}_{2} / \mathrm{Si}$ is not sufficient in the case of $\mathrm{SiC}$ [7]. Nitridation of the $\mathrm{SiO}_{2} / \mathrm{SiC}$ interface, via nitric oxide (NO) or nitrous oxide $\left(\mathrm{N}_{2} \mathrm{O}\right)$ post-oxidation annealing $(\mathrm{POA})$, has emerged as the most effective solution to reduce the pre-irradiation interface trap densities [8]-[14]. Indeed, it significantly improves channel mobility by reducing the $D_{i t}$. Thus, it is of interest to relate the incorporation of nitrogen to the reliability and radiation response of $\mathrm{SiC}$-based devices.

$3 \mathrm{C}-\mathrm{SiC}$ substrate MOS capacitors with as-grown $\mathrm{SiO}_{2}$ gate dielectrics have been shown to be relatively resistant to ionizing radiation-induced degradation [15]. The radiation response of $4 \mathrm{H}-\mathrm{SiC}$ MOS capacitors has also been studied recently [16]-[18]. In 4H-SiC devices, it was demonstrated that a NO POA leads to the suppression of interface trap generation due to electron injection, but also enhances the formation of hole traps, yielding large voltage shifts following X-ray irradiation [19]-[21]. Here we report the total dose radiation response of both 3C- and $4 \mathrm{H}-\mathrm{SiC}$-based MOS capacitors with oxides grown in either $\mathrm{O}_{2}, \mathrm{NO}$ or $\mathrm{N}_{2} \mathrm{O}$, providing a comparison of the reliability of the $\mathrm{SiO}_{2} / \mathrm{SiC}$ interface as a function of the oxidized polytype and of the nitridation processes. The voltage shifts induced by $\mathrm{x}$-ray irradiation are detected using capacitance-voltage $(C-V)$ measurements and discussed in terms of incorporated nitrogen densities extracted by secondary ion mass spectroscopy (SIMS).

\section{DEVICES AND EXPERIMENTS}

The devices considered in this study, processed at Griffith University, are n-substrate $3 \mathrm{C}$ - and $4 \mathrm{H}-\mathrm{SiC}$ MOS capacitors. The starting substrates for the $4 \mathrm{H}-\mathrm{SiC}$ were obtained from Cree Inc., with a high quality $\mathrm{SiC}$ epitaxial layer on top. The $3 \mathrm{C}-\mathrm{SiC}$ was grown on $\mathrm{Si}$, and was obtained from the Institute of Crystal Growth, Germany. Doping densities for $3 \mathrm{C}-$ and $4 \mathrm{H}-\mathrm{SiC}$ are $1.8 \times 10^{16} \mathrm{~cm}^{-3}$ and $2 \times 10^{15} \mathrm{~cm}^{-3}$ respectively. All samples 


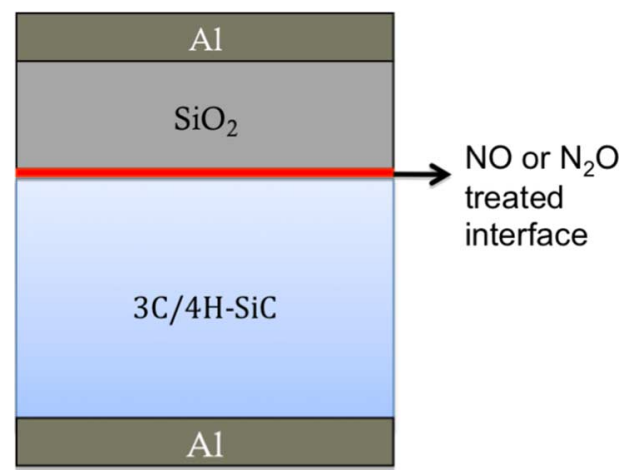

Fig. 1. Schematic diagram of the MOS capacitor structure used in this study.

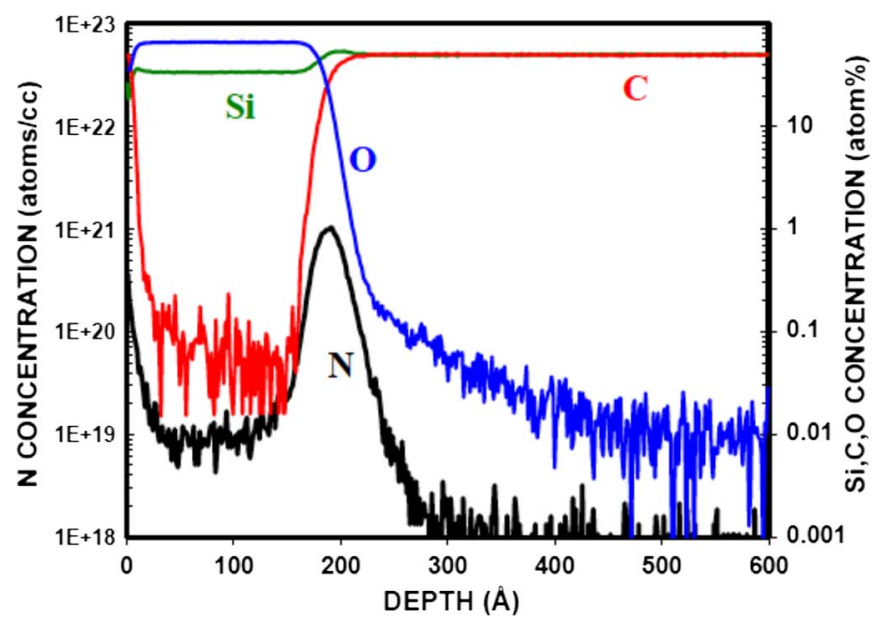

Fig. 2. SIMS profile showing $\mathrm{N}, \mathrm{O}, \mathrm{Si}$ and $\mathrm{C}$ concentration (3C-SiC sample with NO treatment).

were cleaned in a mixture of $\mathrm{H}_{2} \mathrm{SO}_{4}$ and $\mathrm{H}_{2} \mathrm{O}_{2}$ followed by the RCA process. $\mathrm{SiO}_{2}$ gate dielectrics are thermally grown on the (0001) Si face of $4 \mathrm{H}-\mathrm{SiC}$ and on the (001) plane of 3C-SiC. The gate dielectrics were thermally grown using three different processes: 1) dry oxygen at $1185^{\circ} \mathrm{C}$; 2) NO for 2 hours at $1185^{\circ} \mathrm{C}$; 3) $\mathrm{N}_{2} \mathrm{O}$ for 1 hour at $1185^{\circ} \mathrm{C}$. This yielded oxide thicknesses in the $18-25 \mathrm{~nm}$ range. A schematic cross section of the devices is shown in Fig. 1. Aluminum is used for the gate and substrate electrodes.

Irradiation experiments were performed with an ARACOR $10-\mathrm{keV}$ x-ray source at a dose rate of $31.5 \mathrm{krad}\left(\mathrm{SiO}_{2}\right) / \mathrm{min}$. Different biases were applied to the devices during the radiation experiments. Constant voltage stress (CVS) experiments (no radiation) were performed for a duration corresponding to the radiation time in order to separate the effects of bias and irradiation [22]. High frequency (1 MHz) capacitance-voltage $(C-V)$ and conductance-voltage $(G-V)$ measurements were performed between successive irradiation or CVS steps to monitor the change in the midgap voltage $\left(V_{m g}\right)$ [23]. The interface-trap density between 0.2 and $0.6 \mathrm{eV}$ from the $\mathrm{SiC}$ conduction band edge was determined from simultaneous high frequency $(100 \mathrm{kHz})$ and quasi-static $C-V$ measurements made at

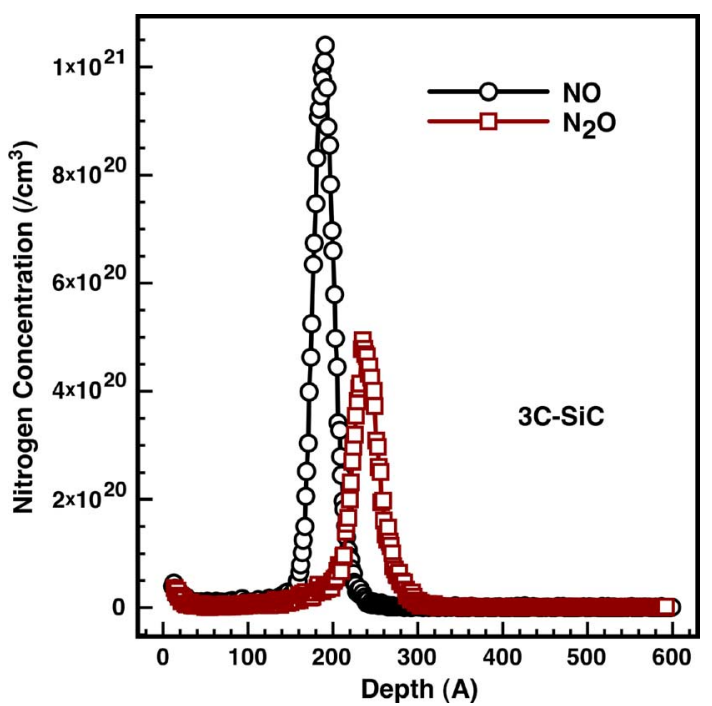

Fig. 3. Nitrogen concentration as a function of depth for 3C-SiC MOS capacitors grown in $\mathrm{NO}$ and $\mathrm{N}_{2} \mathrm{O}$.

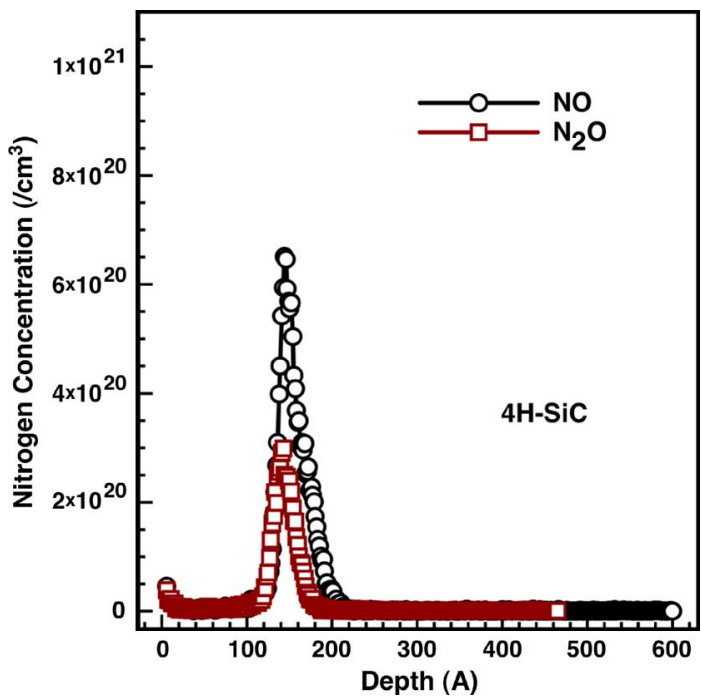

Fig. 4. Nitrogen concentration as a function of depth for $4 \mathrm{H}-\mathrm{SiC}$ MOS capacitors grown in $\mathrm{NO}$ and $\mathrm{N}_{2} \mathrm{O}$.

room temperature. The relation between the gate voltage and the corresponding band gap energy was derived using the Berglund method [24].

SIMS measurements were performed to extract the nitrogen concentrations at the interface. The nitrogen concentrations have been calibrated against a thermal silicon dioxide standard that has been ion implanted with nitrogen. The depth scale has been calibrated against a crater measurement on the same standard sample. Although the absolute values extracted from SIMS are expected to be accurate only within a factor of two, the shapes of the profiles and the relative concentrations between samples provide an excellent basis for direct comparison [21]. 

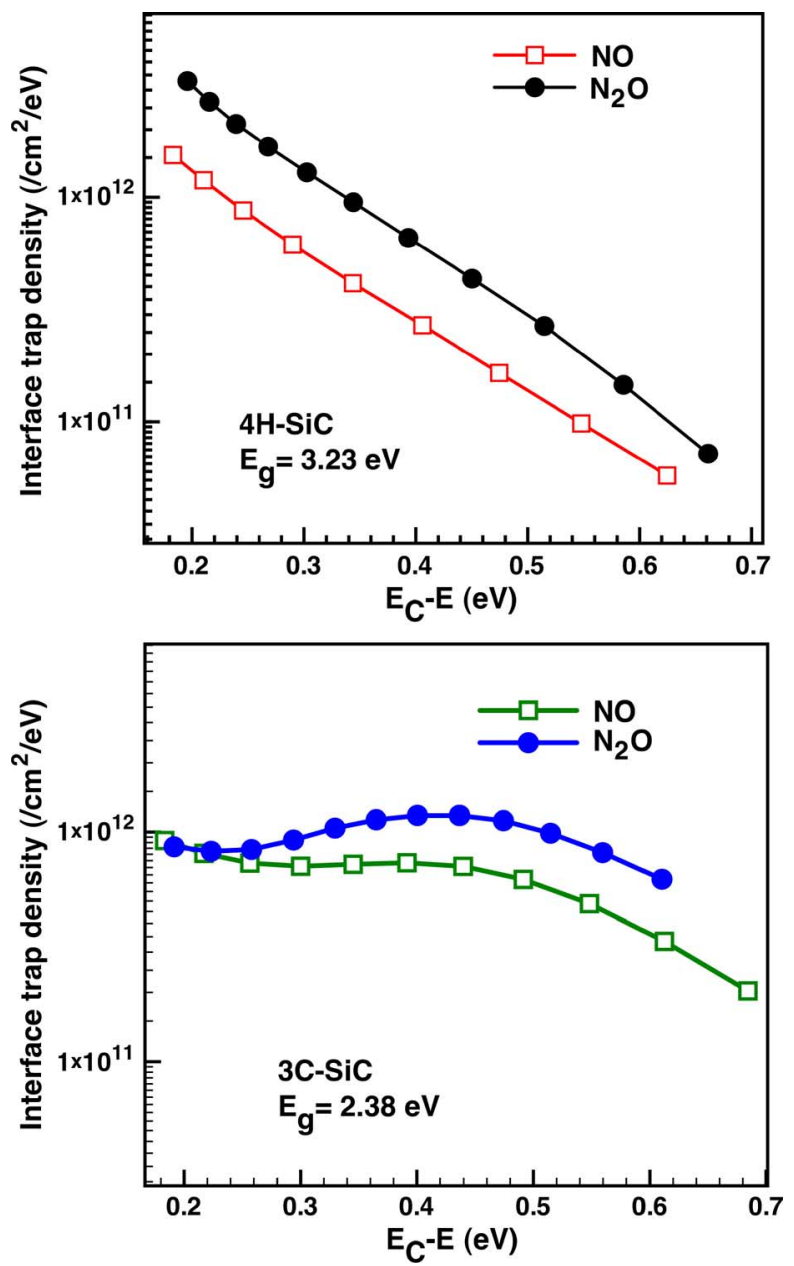

Fig. 5. Interface trap density, $D_{i t}$, as a function of the energy relative to the semiconductor conduction band edges for $4 \mathrm{H}$ - and $3 \mathrm{C}-\mathrm{SiC}$ samples.

\section{RESULTS AND DISCUSSION}

\section{A. SIMS Profiles}

Fig. 2 shows the SIMS profiles for nitrogen $(\mathrm{N})$, carbon $(\mathrm{C})$, oxygen $(\mathrm{O})$, and silicon $(\mathrm{Si})$ for the $3 \mathrm{C}-\mathrm{SiC}$ sample with $\mathrm{NO}$ treatment. Concentrations corresponding to the nitrogen profiles, $\mathrm{N}$, are labeled on the left axis (the depth profile is resolution limited). The $\mathrm{C}, \mathrm{O}$, and $\mathrm{Si}$ concentrations are plotted in arbitrary units on the right axis.

Comparisons of the nitrogen profiles for the $3 \mathrm{C}$ - and $4 \mathrm{H}-\mathrm{SiC}$ MOS capacitors are shown in Figs. 3 and 4. Although the relative positions of the peaks vary because of the slight variations of the oxide thicknesses, we observe the accumulation of nitrogen at the interface between $\mathrm{SiO}_{2}$ and $\mathrm{SiC}$. It is evident that $\mathrm{NO}$ grown oxides result in a greater $\mathrm{N}$ concentration at the interface for both polytypes. Also, $3 \mathrm{C}-\mathrm{SiC}$ has a greater $\mathrm{N}$ concentration for both the $\mathrm{NO}$ and $\mathrm{N}_{2} \mathrm{O}$ processes as compared to $4 \mathrm{H}-\mathrm{SiC}$.

\section{B. Interface-Trap Densities}

The pre-irradiation interface-trap density of all devices is shown in Fig. 5. 3C- and 4H-SiC have different energy band gaps. The valence band edges for $3 \mathrm{C}-$ and $4 \mathrm{H}-\mathrm{SiC}$ are at the same level in energy. Interface-trap densities in the $\mathrm{SiC}$ band

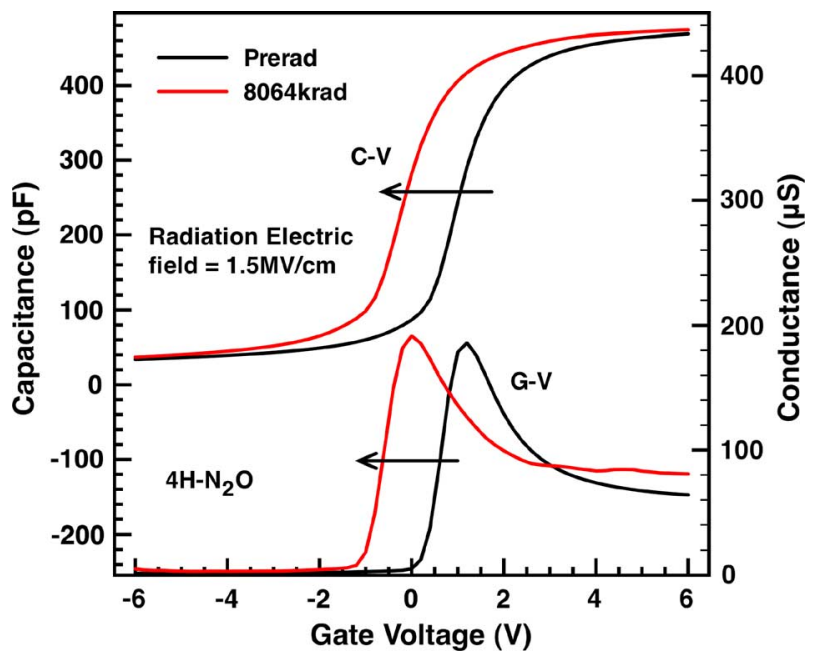

Fig. 6. Capacitance/conductance-voltage characteristics for $4 \mathrm{H}-\mathrm{SiC} \mathrm{MOS}$ with $\mathrm{N}_{2} \mathrm{O}$ treatment (arrows in the figure points to the total dose induced shifts).

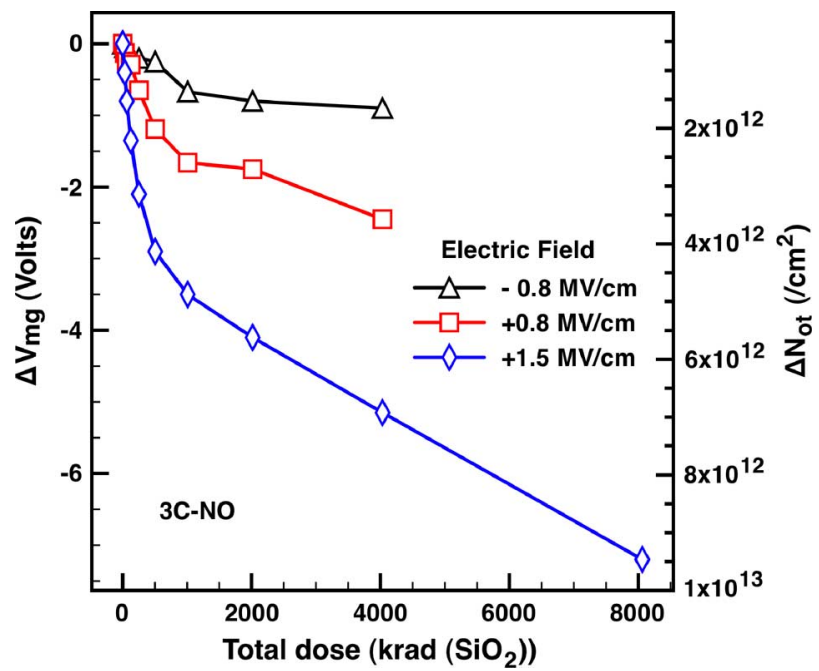

Fig. 7. Shift in midgap voltage as a function of $\mathrm{x}$-ray dose for $3 \mathrm{C}$-SiC MOS capacitors with oxides grown in NO.

gap are asymmetric with a higher density closer to the conduction band edge. The $\mathrm{N}_{2} \mathrm{O}$-grown $3 \mathrm{C}-\mathrm{SiC}$ and $4 \mathrm{H}-\mathrm{SiC}$ devices have a greater interface-trap density than the NO-treated devices. This is consistent with previous reports that NO treatment creates a better oxide-SiC interface than $\mathrm{N}_{2} \mathrm{O}$ treatment [8]. The interface-trap distribution for the oxides on 3C- and $4 \mathrm{H}-\mathrm{SiC}$ is different in the band gap.

\section{Radiation Effects on Interface-Trap Formation}

Fig. 6 shows the $C-V$ and $G-V$ characteristics for $\mathrm{N}_{2} \mathrm{O}$ grown $4 \mathrm{H}-\mathrm{SiC}$ samples before and after $8 \mathrm{Mrad}\left(\mathrm{SiO}_{2}\right)$ total dose irradiation (biased at $+1.5 \mathrm{MV} / \mathrm{cm}$ ). The shift of the $C-V$ and $G-V$ characteristics toward more negative voltage indicates net positive charge trapping. No significant stretch-out of the $C-V$ characteristics is observed, indicating negligible interface-trap formation with radiation within $0.6 \mathrm{eV}$ from the conduction band edge (for all radiation biases studied) [25]. No significant $C-V$ stretch-out was observed for other processes as well. 


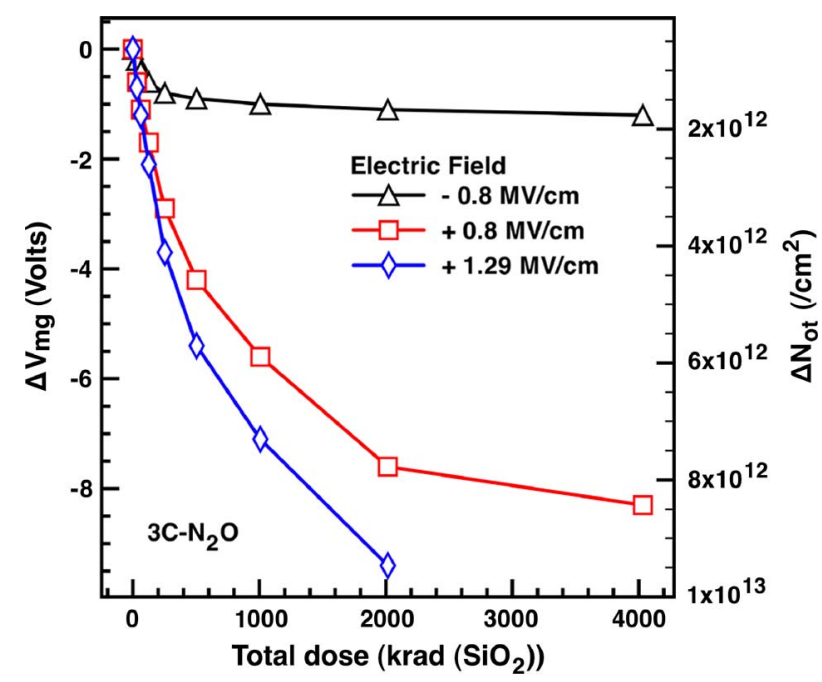

Fig. 8. Shift in midgap voltage as a function of $\mathrm{x}$-ray dose for 3C-SiC MOS capacitors with oxides grown in $\mathrm{N}_{2} \mathrm{O}$.

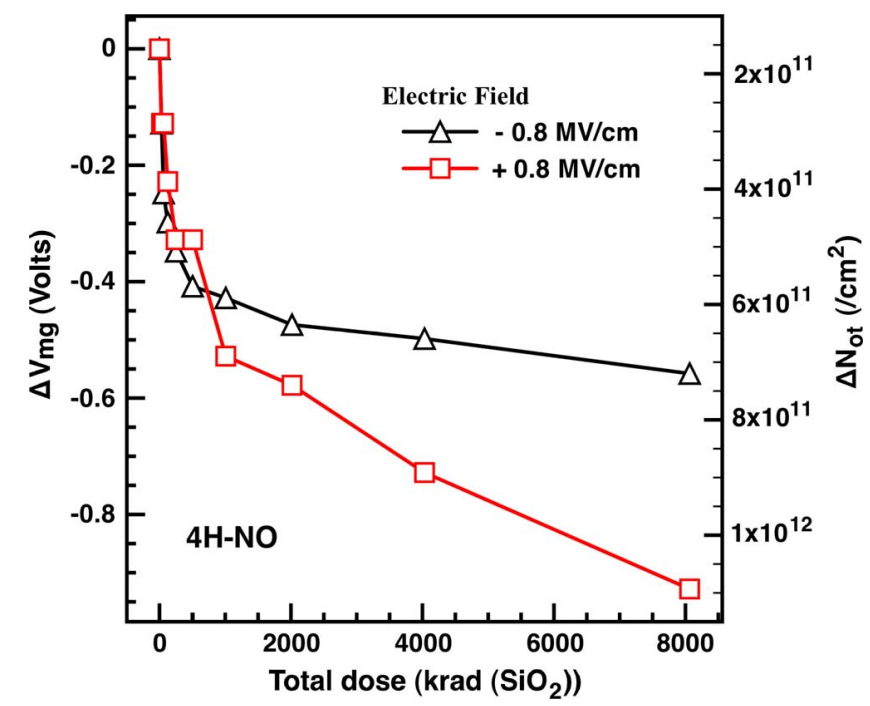

Fig. 9. Midgap voltage shift as a function of $\mathrm{x}$-ray dose for $4 \mathrm{H}-\mathrm{SiC}$ MOS capacitors with oxides grown in NO.

\section{Oxide Trapped Charge}

Figs. 7to 9 show the evolution of the midgap voltage (and the corresponding net trapped charge density) in the various samples upon x-ray irradiation. A constant gate bias corresponding to $+0.8 \mathrm{MV} / \mathrm{cm}$ or $-0.8 \mathrm{MV} / \mathrm{cm}$ was applied during the exposure. In all cases, a buildup of net positive charge was observed. The following expression has been used to calculate the change in net oxide-trap charge density $\left(\Delta N_{o t}\right)$ :

$$
\Delta N_{o t}=-\frac{\Delta V_{m g} C_{o x}}{q}
$$

where $\Delta V_{m g}$ is the shift in midgap voltage, $C_{o x}$ is the oxide capacitance per unit area, and $-q$ is the electron charge. As expected, the shift is greatest for positive gate bias during irradiation as the holes are pushed toward the oxide/semiconductor interface. Higher shifts are observed at higher fields due to a higher fractional yield of the induced e-h pairs. No significant

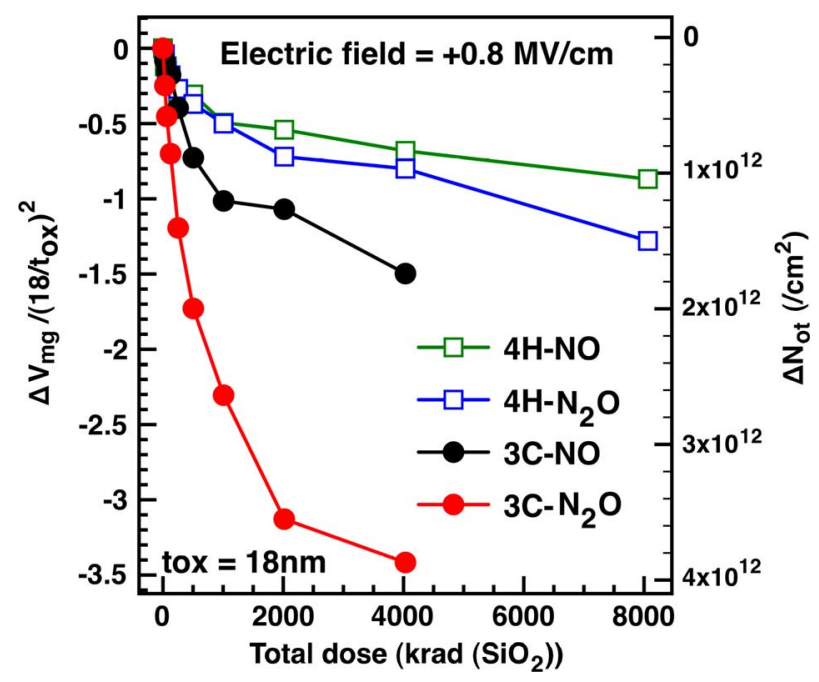

Fig. 10. Normalized midgap voltage shift comparison for $\mathrm{NO}$ and $\mathrm{N}_{2} \mathrm{O}$ oxidation 4H-/3C-SiC MOS sample.

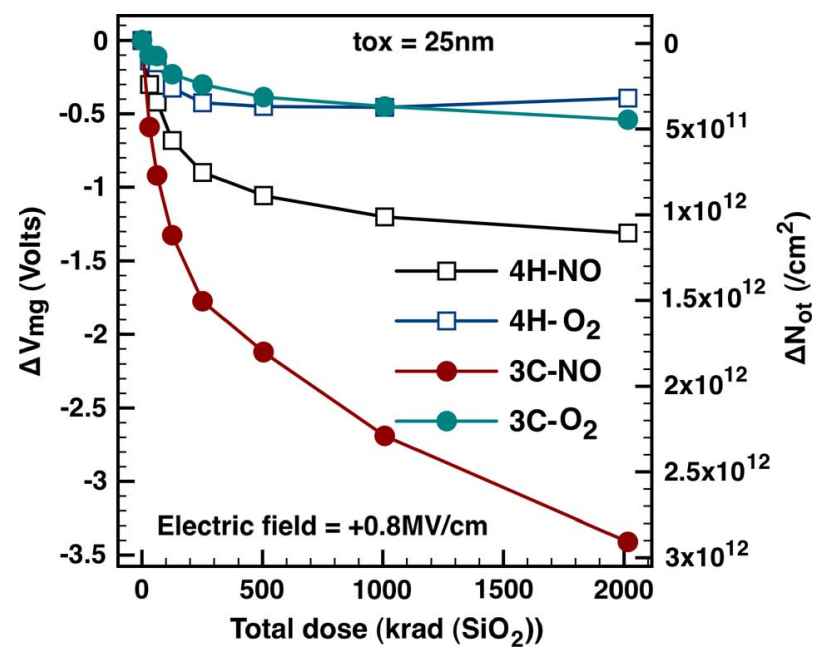

Fig. 11. Midgap voltage shift comparison for NO oxidized and as-oxidized 3Cand $4 \mathrm{H}-\mathrm{SiC}$ MOS of the same oxide thickness.

stretch-out of the high frequency $C-V$ curves with irradiation and/or CVS is observed, indicating that the density of interface traps generated by irradiation and/or electrical stress is not significant in these devices.

In contrast, a noticeable increase in the stretch-out was reported in previous studies of radiation effects on 3C-SiC MOS devices that did not have a nitrided interlayer [15]. This suggests that nitridation improves the interface by preventing interface-trap generation during reliability stress conditions [26]. However, the flatband voltage shifts can be quite large under positive bias, in agreement with recent observations showing that nitriding the $\mathrm{SiO}_{2} / \mathrm{SiC}$ interface increases the density of net positive oxide-trap charge [20], [21].

CVS measurements performed at equivalent positive biases show that there is a relatively small amount of background electron trapping in the $4 \mathrm{H}-\mathrm{SiC}$ devices, and none is detected in the $3 \mathrm{C}-\mathrm{SiC}$ devices. Because the magnitude of charge trapping produced by CVS is much smaller than the radiation-induced charge trapping, the compensating effects of electron injection 

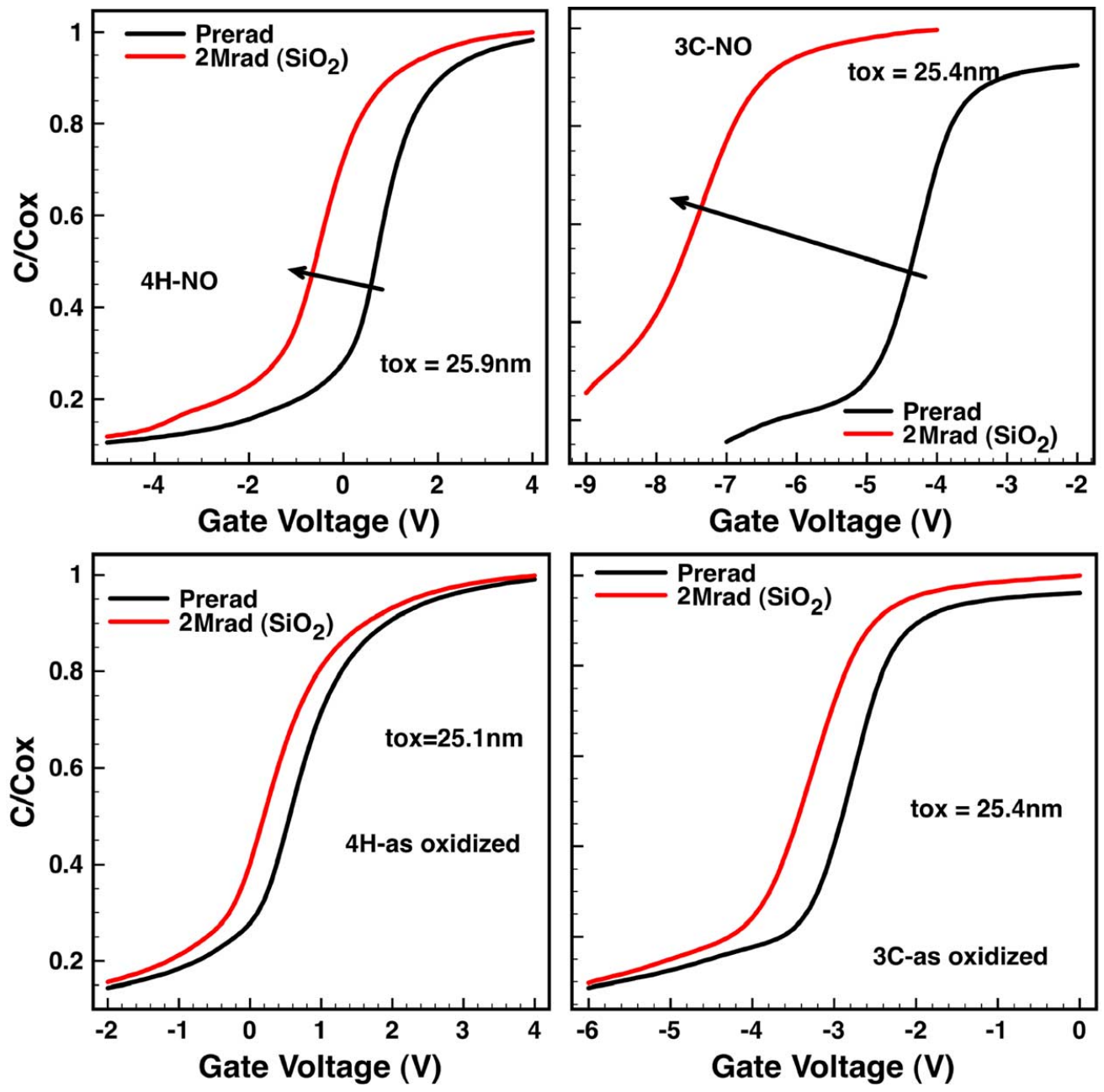

Fig. 12. Capacitance-voltage characteristics for $4 \mathrm{H}-\mathrm{NO}, 3 \mathrm{C}-\mathrm{NO}, 4 \mathrm{H}$-as oxidized, and $3 \mathrm{C}$-as oxidized $\mathrm{MOS}$ samples before and after a total dose of $2 \mathrm{Mrad}\left(\mathrm{SiO} \mathrm{O}_{2}\right)$.

into shallow traps [22] are small in these devices, and do not greatly impact the radiation-induced voltage shifts.

Oxides processed on different substrates and with different oxidation conditions had slightly different oxide thicknesses (in the $18-25 \mathrm{~nm}$ range), making it difficult to make a direct comparison of the trapped densities. We therefore attempt to normalize the data to compare the charge buildup and the resulting voltage shifts. Assuming that the centroids of the oxide-trap charge distributions are located at similar distances from the $\mathrm{SiC} / \mathrm{SiO}_{2}$ interface and that interface-trap charge densities are small compared to oxide-trap charge densities, it can be shown in the dose range where oxide-trap charge increases monotonically with dose (e.g., below $\sim 2 \mathrm{Mrad}\left(\mathrm{SiO}_{2}\right)$ that [27]

$$
\Delta V_{m g} \propto t_{o x}^{2}
$$

for a given oxide field, where $t_{o x}$ is the oxide thickness. Accordingly, the observed trends in charge trapping discussed below are larger than those associated with simple oxide thickness differences.

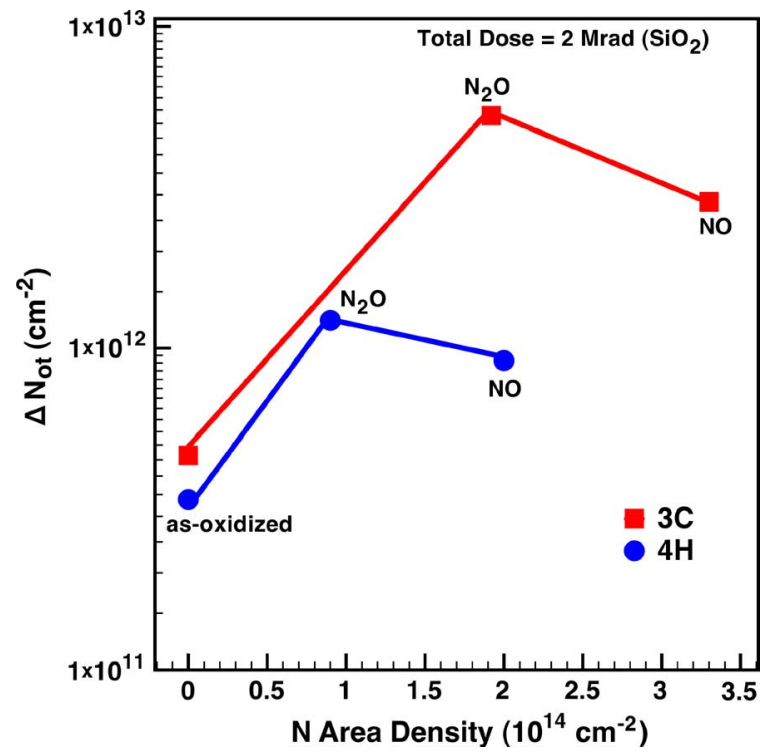

Fig. 13. Comparison of net positive oxide-trapped charge density as a function of nitrogen areal density for the 6 samples (3C-as oxidized, $3 \mathrm{C}-\mathrm{N}_{2} \mathrm{O}, 3 \mathrm{C}-\mathrm{NO}$, $4 \mathrm{H}$-as oxidized, $4 \mathrm{H}-\mathrm{N}_{2} \mathrm{O}, 4 \mathrm{H}-\mathrm{NO}$ ). 


\section{E. Comparison of Trapped Charge}

Fig. 10 compares the midgap-voltage shift for the NOand $\mathrm{N}_{2} \mathrm{O}$-treated oxides on both substrates. The data for the $3 \mathrm{C}-\mathrm{SiC}\left(\mathrm{NO}\right.$ and $\left.\mathrm{N}_{2} \mathrm{O}\right)$ and $4 \mathrm{H}-\mathrm{SiC}(\mathrm{NO})$ devices are normalized with respect to the data for the $4 \mathrm{H}-\mathrm{SiC}\left(\mathrm{N}_{2} \mathrm{O}\right)$ devices (oxide thickness $=17.9 \mathrm{~nm}$ ). A greater density of trapped oxide charge is observed for oxides on the $3 \mathrm{C}-\mathrm{SiC}$ substrates. This may be because the crystal quality of the CVD-grown $3 \mathrm{C}-\mathrm{SiC}$ is not as good as the $4 \mathrm{H}-\mathrm{SiC}[28]$. The $4 \mathrm{H}-\mathrm{SiC}$ material is grown by the modified Lely (sublimation) method and has an epi layer grown on top of it by CVD. In the case of 3C-SiC the difference of the crystal lattice constant between $\mathrm{Si}$ and $\mathrm{SiC}$ leads to a significant density of defects and stacking faults for the $3 \mathrm{C}-\mathrm{SiC}$ substrates. Other factors that may lead to differences in charge trapping for the two polytypes are the different crystalline structures and orientations, yielding different semiconductor surface properties, as well as the different band gaps ( $\sim 3.23 \mathrm{eV}$ for $4 \mathrm{H}-\mathrm{SiC}$ and $\sim 2.38 \mathrm{eV}$ for $3 \mathrm{C}-\mathrm{SiC}$ ).

The dominant hole trap in nitrided $4 \mathrm{H}-\mathrm{SiC}$ has been recently linked to defect configurations involving $\mathrm{N}$ in the near-interface region [20]. Furthermore, it has been shown for the $4 \mathrm{H}-\mathrm{SiC}$ case that the trapped charge density is linearly proportional to the $\mathrm{N}$ content [21]. The oxide-trap charge density is greater for the $\mathrm{N}_{2} \mathrm{O}$-treated $3 \mathrm{C}$-SiC devices, indicating that the interface quality is not as good as for the NO-treated samples, consistent with the linearity mentioned above. The $3 \mathrm{C}-\mathrm{SiC}$ samples contain more nitrogen than $4 \mathrm{H}-\mathrm{SiC}$ samples, as shown above.

The oxidation kinetics of the two nitrogen containing gases, $\mathrm{NO}$ and $\mathrm{N}_{2} \mathrm{O}$, are different, Thus their impact on the electrical properties are not the same, as demonstrated by SIMS and $D_{i t}$ measurements, and further observed through the differences in positive charge buildup. According to calculations of Gupta et al., the $\mathrm{N}_{2} \mathrm{O}$ gas dissociates into $\mathrm{NO}(15 \%), \mathrm{O}_{2}(25.7 \%)$ and $\mathrm{N}_{2}(59.3 \%)$ at $1130{ }^{\circ} \mathrm{C}$ [29]. The molar ratio of $\mathrm{O}_{2}$ to $\mathrm{NO}$ is $\sim 0.5$ and 3 during $\mathrm{NO}$ and $\mathrm{N}_{2} \mathrm{O}$ anneals, respectively [30]. The greater $\mathrm{O}_{2}$ content due to dissociation of $\mathrm{N}_{2} \mathrm{O}$ leads to competing reactions. NO incorporates nitrogen and oxidizes the substrate at a lower rate; whereas, $\mathrm{O}_{2}$ causes a higher oxidation rate. The NO component resulting from the decomposition of $\mathrm{N}_{2} \mathrm{O}$ causes the same chemical reactions and effects that occur in the cases of pure NO nitridation, but it is accompanied by substantial additional oxidation, with a correspondingly high defect creation in competition with the beneficial effects of the nitrogen. This competition favors more nitrogen incorporation in the case of $\mathrm{NO}$, and possibly a higher concentration of $\mathrm{O}$ vacancies (also efficient hole traps in nitrided oxides [31]) in the $\mathrm{N}_{2} \mathrm{O}$ oxides.

To further analyze the role of nitrogen at the interface on charge trapping in nitrided samples, we compared the charge buildup results in as-oxidized and NO-grown samples. Fig. 11 shows the results for both polytypes. In this case no normalization was necessary as the oxide thicknesses were very similar (within $1 \mathrm{~nm}$ ). It is clearly seen that NO treated 3C samples trap more charge than $4 \mathrm{H}-\mathrm{SiC}$ samples with the same treatment. The as-oxidized $3 \mathrm{C}$ - and $4 \mathrm{H}-\mathrm{SiC}$ MOS samples trapped much less net oxide-trap charge than those which underwent $\mathrm{NO}$ nitridation, directly confirming that the nitridation process leads to higher net positive trapping (Figs. 11, 12). The very small midgap voltage shifts in as-oxidized samples may either result from less hole trapping, or from compensating deep interface traps at the $\mathrm{SiC} / \mathrm{SiO}_{2}$ interface, which appear as fixed charges in these wide band gap $\mathrm{SiC}$ devices [4].

\section{F. Discussion}

Fig. 13 shows the shift in oxide trapped charge density vs. the $\mathrm{N}$ areal density for both polytypes at a total radiation dose of $2 \mathrm{Mrad}\left(\mathrm{SiO}_{2}\right)$. It has been shown previously that increasing the $\mathrm{N}$ areal density due to NO post-oxidation anneal results in consistently increasing net positive oxide trapped charge density [20], [21]. We see the same linear trend when comparing the as-oxidized samples to either the $\mathrm{NO}$ or $\mathrm{N}_{2} \mathrm{O}$ grown oxides, further indicating that $\mathrm{N}$ plays a significant role in charge buildup.

In contrast, Fig. 13 suggests that this monotonic trend of increasing trapping with $\mathrm{N}$ content is not obeyed in the case where the $\mathrm{N}$ has been incorporated by different growth conditions (NO or $\mathrm{N}_{2} \mathrm{O}$ ). $\mathrm{N}_{2} \mathrm{O}$ oxidized samples trap more charge, although they have lower $\mathrm{N}$ areal density. This may be attributed to the degraded quality of the interface after $\mathrm{N}_{2} \mathrm{O}$ treatment, associated with an increase of $\mathrm{O}$ vacancies, as discussed above [31].

The 3C-SiC devices trapped more charge than $4 \mathrm{H}-\mathrm{SiC}$ devices for any kind of nitridation. The results suggests that greater charge trapping on $3 \mathrm{C}$ - as compared to $4 \mathrm{H}-\mathrm{SiC}$ is at least partly due to greater nitrogen concentration at the interface of $3 \mathrm{C}$-SiC. When looking at a given nitridation process, the trend between charge buildup and nitrogen concentration indicate the origin of the traps may be similar in oxides grown on both polytypes, despite the difference in the crystal structure, orientation, quality, and band gap.

\section{CONCLUSION}

Oxides grown on $3 \mathrm{C}$-SiC substrates trap more charge than those grown on $4 \mathrm{H}-\mathrm{SiC}$ substrates. $\mathrm{N}_{2} \mathrm{O}$-annealed oxides trap more charge for both $3 \mathrm{C}$ - and $4 \mathrm{H}-\mathrm{SiC}$ substrates than do the NO-annealed oxides. $\mathrm{N}_{2} \mathrm{O}$-annealed oxides also have higher interface trap densities before irradiation. No significant generation of interface traps is observed for any of the nitride oxide samples after irradiation within 0.2 and $0.6 \mathrm{eV}$ from the conduction band edge. We link greater charge trapping in the $3 \mathrm{C}$ devices compared to the $4 \mathrm{H}-\mathrm{SiC}$ devices to the greater nitrogen content at the interface for $3 \mathrm{C} . \mathrm{N}_{2} \mathrm{O}$ follows different reaction kinetics and traps more oxide charge than NO, despite having a lower $\mathrm{N}$ concentration at the interface. Additional trapped positive charge in $\mathrm{N}_{2} \mathrm{O}$-treated devices may possibly be correlated to $\mathrm{O}$ vacancies in $\mathrm{SiO}_{2}$.

Although $\mathrm{N}$ seems to play a role in the trapping process, we have observed that it is not the only factor to take into account. Indeed, the details of the nitridation and the nature of the substrate are also key parameters defining the quality of the oxide/semiconductor interface.

\section{REFERENCES}

[1] J. A. Cooper, Jr., M. R. Melloch, R. Singh, A. Agarwal, and J. W. Palmour, "Status and prospects of SiC power MOSFETs," IEEE Trans. Electron Devices, vol. 49, pp. 658-664, 2002. 
[2] M. Bhatnagar and B. J. Baliga, "Comparison of 6H-SiC, 3C-SiC, and $\mathrm{Si}$ for power devices," IEEE Trans. Electron Devices, vol. 40, pp. 645-655, 1993.

[3] H. Morkoc, S. Strite, G. B. Gao, M. E. Lin, B. Sverdlov, and M. Burns, "Large band-gap SiC, III-V nitride, and II-VI ZnSe-based semiconductor device technologies," J. Appl. Phys., vol. 76, pp. 1363-1398, 1998.

[4] J. A. Cooper, Jr., "Critical material and processing issues of SiC electronic devices," Mater. Sci. Eng., vol. 44, pp. 387-391, 1997.

[5] D. L. Barrett and R. B. Campbell, "Electron mobility measurements in SiC polytypes," J. Appl. Phys., vol. 38, pp. 53-55, 1967.

[6] A. J. Steckl, C. Yuan, J. P. Li, and M. J. Loboda, "Growth of crystalline $3 \mathrm{C}$-SiC on $\mathrm{Si}$ at reduced temperatures by chemical vapor deposition from silacyclobutane," Appl. Phys. Lett., vol. 63, pp. 3347-3349, 1993.

[7] V. V. Afanas'ev, M. Bassler, G. Pensl, and M. Schulz, "Intrinsic $\mathrm{SiC} / \mathrm{SiO}_{2}$ interface states," Phys. Status Solidi, vol. 162, pp. 321-337, 1997.

[8] H. F. Li, S. Dimitrijev, H. B. Harrison, and D. Sweatman, "Interfacial characteristics of $\mathrm{N}_{2} \mathrm{O}$ and $\mathrm{NO}$ nitrided $\mathrm{SiO}_{2}$ grown on $\mathrm{SiC}$ by rapid thermal processing," Appl. Phys. Lett., vol. 70, pp. 2028-2030, 1997.

[9] G. Y. Chung C. C. Tin, J. R. Williams, K. McDonald, R. K. Chanana, R. A. Weller, S. T. Pantelides, L. C. Feldman, O. W. Holland, M. K. Das, and J. W. Palmour, "Improved inversion channel mobility for 4H-SiC MOSFETs following high temperature anneals in nitric oxide," IEEE Electron Device Lett., vol. 22, pp. 176-178, 2001.

[10] P. Jamet, S. Dimitrijev, and P. Tanner, "Effects of nitridation in gate oxides grown on 4H-SiC," J. Appl. Phys., vol. 90, no. 10, pp. 5058-5063, 2001.

[11] R. Schorner, P. Friedrichs, D. Peters, D. Stephani, S. Dimitrijev, and P. Jamet, "Enhanced channel mobility of $4 \mathrm{H}-\mathrm{SiC}$ MOSFETs fabricated with standard power MOSFET technology and gate-oxide nitridation," Appl. Phys. Lett., vol. 80, pp. 4253-4256, 2002.

[12] K. McDonald, R. A. Weller, S. T. Pantelides, L. C. Feldman, G. Y. Chung, C. C. Tin, and J. R. Williams, "Characterization and modeling of the nitrogen passivation of interface traps in $\mathrm{SiO}_{2} / 4 \mathrm{H}-\mathrm{SiC}$," $J$. Appl. Phys., vol. 93, pp. 2719-2722, 2003.

[13] S. Dhar, Y. W. Song, L. C. Feldman, T. Isaacs-Smith, C. C. Tin, J. R. Williams, G. Chung, T. Nishimura, D. Starodub, T. Gustafsson, and E. Garfunkel, "Effect of nitric oxide annealing on the interface trap density near the conduction band edge of $4 \mathrm{H}-\mathrm{SiC}$ at the oxide/(1120) 4H-SiC interface," Appl. Phys. Lett., vol. 84, pp. 1498-1500, 2004.

[14] G. V. Soares, I. J. R. Baumvol, L. Hold, F. Kong, J. Han, S. Dimitrijev, C. Radtke, and F. C. Stedile, "Sequential thermal treatments of SiC in $\mathrm{NO}$ and $\mathrm{O}_{2}$ : Atomic transport and electrical characteristics," Appl. Phys. Lett., vol. 91, no. 041906, pp. 1-3, 2007.

[15] M. Yoshikawa, H. Itoh, Y. Morita, I. Nashiyama, S. Misawa, H. Okumura, and S. Yoshida, "Effects of gamma-ray irradiation on cubic silicon carbide metal-oxide-semiconductor structure," J. App. Phys., vol. 70, pp. 1309-1312, 1991.

[16] T. Chen, Z. Luo, J. D. Cressler, T. F. Isaacs-Smith, J. R. Williams, G. Chung, and S. D. Clark, "Effects of NO passivation on the radiation response of $\mathrm{SiO}_{2} / 4 \mathrm{H}-\mathrm{SiC}$ MOS capacitors," Solid State Electron., vol. 46, pp. 2231-2235, 2002.
[17] Z. Luo, T. Chen, A. C. Ahyi, A. K. Sutton, B. M. Haugerud, J. D. Cressler, D. C. Sheridan, J. R. Williams, P. W. Marshall, and R. A. Reed, "Proton radiation effects in $4 \mathrm{H}-\mathrm{SiC}$ diodes and MOS capacitors," IEEE Trans. Nucl. Sci., vol. 51, pp. 3748-3752, 2004.

[18] D. C. Sheridan, G. Chung, S. Clark, and J. D. Cressler, "The effects of high-dose gamma irradiation on high-voltage $4 \mathrm{H}-\mathrm{SiC}$ Schottky diodes and the $\mathrm{SiC}-\mathrm{SiO}_{2}$ interface," IEEE Trans. Nucl. Sci., vol. 48, pp. 2229-2232, 2001

[19] S. K. Dixit, S. Dhar, J. Rozen, S. Wang, R. D. Schrimpf, D. M. Fleetwood, S. T. Pantelides, J. R. Williams, and L. C. Feldman, "Total dose radiation response of nitrided and non-nitrided $\mathrm{SiO}_{2} / 4 \mathrm{H}-\mathrm{SiC}$ MOS capacitors," IEEE Trans. Nucl. Sci., vol. 53, pp. 3687-3692, 2006.

[20] J. Rozen, S. Dhar, S. K. Dixit, V. V. Afanas'ev, F. O. Roberts, H. L. Dang, S. Wang, S. T. Pantelides, J. R. Williams, and L. C. Feldman, "Increase in oxide hole trap density associated with nitrogen incorporation at the $\mathrm{SiO}_{2} / \mathrm{SiC}$ interface," J. Appl. Phys., vol. 103, p. 124513 , 2008.

[21] J. R. Rozen, S. Dhar, M. E. Zvanut, J. R. Williams, and L. C. Feldman, "Density of interface states, electron traps, and hole traps, as a function of the nitrogen density in $\mathrm{SiO}_{2}$ on SiC," J. Appl. Phys., vol. 105, p. 124506, 2009.

[22] S. K. Dixit, X. J. Zhou, R. D. Schrimpf, D. M. Fleetwood, S. T. Pantelides, R. Choi, G. Bersuker, and L. C. Feldman, "Radiation induced charge trapping in ultrathin $\mathrm{HfO}_{2}$-based MOSFETs," IEEE Trans. Nucl. Sci., vol. 54, pp. 1883-1890, 2007.

[23] E. H. Nicollian and J. R. Brews, MOS Physics and Technology. New York: Wiley, 2003.

[24] C. N. Berglund, "Surface states at steam-grown silicon-silicon dioxide interfaces," IEEE Trans. Electron Devices, vol. 13, pp. 701-705, 1966

[25] P. J. McWhorter and P. S. Winokur, "Simple technique for separating the effects of interface traps and trapped-oxide charge in MOS transistors," Appl. Phys. Lett., vol. 48, pp. 133-135, 1986.

[26] F. L. Terry, R. J. Aucoin, and M. L. Naiman, "Radiation effects in nitride oxides," IEEE Electron Device Lett., vol. 4, no. 6, pp. 191-193, Jun. 1983.

[27] H. E. Boesch, Jr., F. B. McLean, J. M. Benedetto, J. M. McGarrity, and W. E. Bailey, "Saturation of threshold voltage shift in MOSFET's at high total dose," IEEE Trans. Nucl. Sci., vol. 33, pp. 1191-1197, 1986.

[28] W. L. Choyke, H. Matsunami, and G. Pensl, "Silicon carbide: Recen major advances," in Advanced Texts in Physics. Berlin, Germany: Springer, 2004

[29] A. Gupta, S. Toby, E. P. Gusev, H. C. Lu, Y. Li, M. L. Green, T. Gustafsson, and E. Garfunkel, "Nitrous oxide gas phase chemistry during silicon oxynitride film growth," Progr. Surface Sci., vol. 59, pp. $103-115,1998$

[30] K. McDonald, L. C. Feldman, R. A. Weller, G. Y. Chung, C. C. Tin and J. R. Williams, "Kinetics of NO nitridation in $\mathrm{SiO}_{2} / 4 \mathrm{H}-\mathrm{SiC}$," J. Appl. Phys., vol. 93, pp. 2257-2261, 2003.

[31] D. M. Fleetwood and N. S. Saks, "Oxide, interface, and border traps in thermal, $\mathrm{N}_{2} \mathrm{O}$, and $\mathrm{N}_{2} \mathrm{O}$-nitrided oxides," J. Appl. Phys., vol. 79, pp. $1583-1594,1996$. 